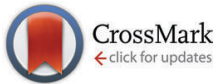

Cite this: Phys. Chem. Chem. Phys., 2016, 18, 25221

Received 16th June 2016, Accepted 5th August 2016

DOI: $10.1039 / c 6 c p 04221 j$

www.rsc.org/pccp

\section{Pushing up the magnetisation values for iron oxide nanoparticles via zinc doping: $X$-ray studies on the particle's sub-nano structure of different synthesis routes $\dagger$}

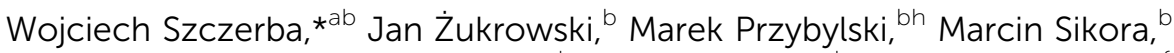 \\ Olga Safonova, ${ }^{c}$ Aleksey Shmeliov, ${ }^{d}$ Valeria Nicolosi, ${ }^{d}$ Michael Schneider, ${ }^{e f}$ \\ Tim Granath, ${ }^{\dagger}$ Maximilian Oppmann, ${ }^{9}$ Marion Straßer ${ }^{e}$ and Karl Mandel ${ }^{*}{ }^{e f}$
}

\begin{abstract}
The maximum magnetisation (saturation magnetisation) obtainable for iron oxide nanoparticles can be increased by doping the nanocrystals with non-magnetic elements such as zinc. Herein, we closely study how only slightly different synthesis approaches towards such doped nanoparticles strongly influence the resulting sub-nano/atomic structure. We compare two co-precipitation approaches, where we only vary the base $\left(\mathrm{NaOH}\right.$ versus $\mathrm{NH}_{3}$ ), and a thermal decomposition route. These methods are the most commonly applied ones for synthesising doped iron oxide nanoparticles. The measurable magnetisation change upon zinc doping is about the same for all systems. However, the sub-nano structure, which we studied with Mössbauer and X-ray absorption near edge spectroscopy, differs tremendously. We found evidence that a much more complex picture has to be drawn regarding what happens upon $\mathrm{Zn}$ doping compared to what textbooks tell us about the mechanism. Our work demonstrates that it is crucial to study the obtained structures very precisely when "playing" with the atomic order in iron oxide nanocrystals.
\end{abstract}

\section{Introduction}

Magnetic nanoparticles have aroused much interest in recent years which will certainly continue in the future as tiny magnetic objects bear much potential for a huge variety of applications. For instance, their potential in the following fields has been demonstrated: biotechnology/biomedicine, ${ }^{1}$ magnetic resonance imaging, ${ }^{2,3}$ catalysis, ${ }^{4,5}$ magnetic fluids, ${ }^{6}$ environmental remediation $^{7,8}$ and data storage. ${ }^{9}$

\footnotetext{
${ }^{a}$ Bundesanstalt für Materialforschung und -prüfung (BAM), Unter den Eichen 87 , 12205 Berlin, Germany. E-mail: wojciech.szczerba@bam.de

${ }^{b}$ Academic Centre for Materials and Nanotechnology, AGH University of Science and Technology, al. Mickiewicza 30, 30-059 Kraków, Poland

${ }^{c}$ Swiss Light Source, Paul Scherrer Institute, 5232 Villigen, Switzerland

${ }^{d}$ Trinity College Dublin, School of Chemistry, School of Physics \& CRANN, Dublin 2, Ireland

${ }^{e}$ Fraunhofer Institute for Silicate Research ISC, Neunerplatz 2, 97082 Wuerzburg, Germany. E-mail: karl-sebastian.mandel@isc.fraunhofer.de

${ }^{f}$ Department of Chemical Technology of Materials Synthesis, University of Wuerzburg, Roentgenring 11, 97070 Wuerzburg, Germany

${ }^{g}$ Fraunhofer Institute for Interfacial Engineering and Biotechnology IGB, Translational Center "Regenerative Therapies for Oncology and Musculoskeletal Diseases", Roentgenring 11, 97070 Wuerzburg, Germany

${ }^{h}$ Faculty of Physics and Applied Computer Science, AGH University of Science and Technology, al. Mickiewicza 30, 30-059 Kraków, Poland

$\dagger$ Electronic supplementary information (ESI) available. See DOI: 10.1039/с6сp04221j
}

Although the fields where magnetic nanoparticles are envisaged to be utilised are very different and thus demand different properties, there is mostly one thing in common; under an externally applied field, the magnetic nanoparticles should be as strongly magnetic as possible, as only then can they be turned into active actuators.

The most prominent class of nanomagnetic particles are iron oxides. Which are attractive because they show good magnetic properties, are easily synthesised, the elements are abundant, and not to forget that iron is not toxic, compared to nickel or cobalt for instance.

Among the class of magnetic iron oxides, maghemite $\left(\gamma-\mathrm{Fe}_{2} \mathrm{O}_{3}\right)$ and magnetite $\left(\mathrm{Fe}_{3} \mathrm{O}_{4}\right)$, are relevant as all other iron oxide forms are inferior with respect to magnetic properties. In bulk, magnetite and maghemite are ferrimagnetic materials with a remarkable saturation magnetisation of $92-100 \mathrm{emu}^{-1}$ and 60-80 emu g ${ }^{-1}$, respectively. ${ }^{10}$

Unfortunately, the saturation magnetisation, $M_{\mathrm{s}}$, of a bulk ferro- or ferrimagnetic material is usually higher than for nanoparticles of the same material. ${ }^{11}$ The main reason for the drop of $M_{\mathrm{s}}$ is the high fraction of atoms on the surface of a nanoparticle. At the surface, the atoms have different coordination as well as dangling bonds. This leads to misalignment of spins (frustrated spins) and thus a shell of atoms that do not contribute to the total magnetisation. ${ }^{12}$ Furthermore, surface oxide effects are 
(a)

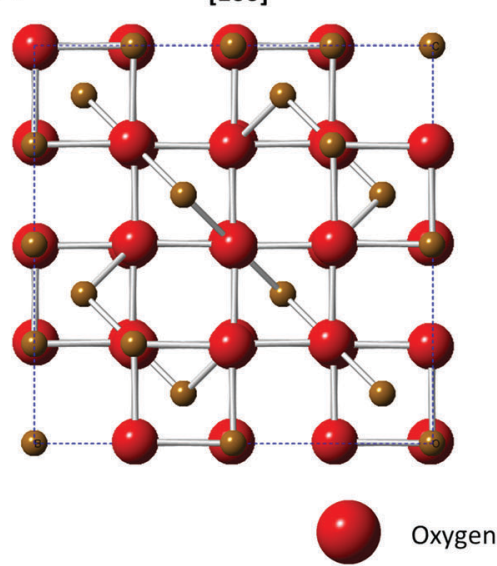

(b)

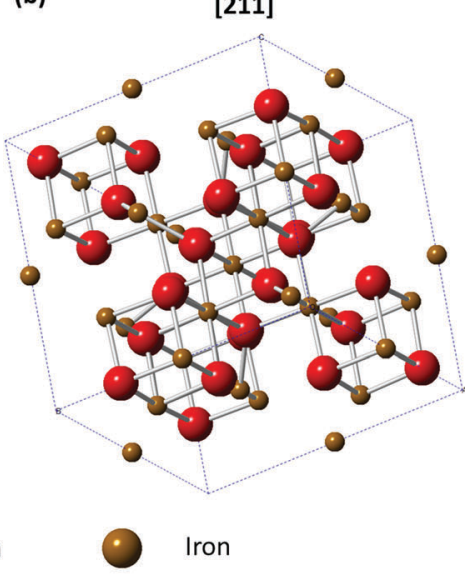

(c)

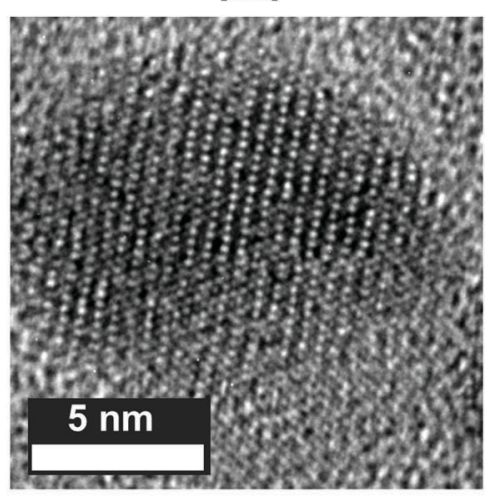

Fig. 1 (a and b) Structural models of magnetite along [100] and [211] view directions. (c) HRTEM image of an iron oxide nanoparticle with spinel structure along [211] view direction.

also encountered which might reduce the total magnetisation of a particle. ${ }^{12}$

However, this draw-back can be overcome by engineering the arrangement of the magnetic moments in the nanocrystals. The magnetisation results from the sum of the vectors of the magnetic atomic moments within the crystal.

Magnetite $\left(\mathrm{Fe}_{3} \mathrm{O}_{4}\right)$ possesses an inverse spinel structure. ${ }^{10}$ It has a face centred cubic unit cell with $32 \mathrm{O}^{2-}$ closed packed along [111] which yields 8 formula units per unit cell. ${ }^{10}$ Remarkably, the iron oxide magnetite contains $\mathrm{Fe}(\mathrm{II})$ in its unit cell. The formula can be written as $\mathrm{Fe}(\mathrm{III})[\mathrm{Fe}(\mathrm{III}) \mathrm{Fe}(\mathrm{III})] \mathrm{O}_{4}$. One-eighth of the tetrahedral sites are occupied by Fe(III), and one-half of the octahedral sites are occupied by Fe(II) and Fe(III) (Fig. 1). ${ }^{13}$ The atomic magnetic moments of the tetrahedral sites ("A sites"; occupied with $\mathrm{Fe}(\mathrm{III})$ ) and the octahedral sites ("B sites"; occupied with $\mathrm{Fe}(\mathrm{II})$ and $\mathrm{Fe}(\mathrm{III})$ ), quantum mechanically interacting via a $127^{\circ} \mathrm{Fe}-\mathrm{O}-\mathrm{Fe}$ linkage, align anti-parallel to each other. The B sites ( $\mathrm{Fe}(\mathrm{II})$ and $\mathrm{Fe}(\mathrm{III})$ ) align parallel to each other. ${ }^{10}$ Thus at $0 \mathrm{~K}$, the magnetic moment of $\mathrm{Fe}_{3} \mathrm{O}_{4}$ is $4 \mu_{\mathrm{B}}$ ( $(5$ unpaired d-electrons from $\mathrm{Fe}(\mathrm{III}))-(5+4$ unpaired d-electrons from $\mathrm{Fe}(\mathrm{III})$ and $\left.\mathrm{Fe}(\mathrm{II}))=4 \mu_{\mathrm{B}}\right)$, with $\mu_{\mathrm{B}}$ symbolising the Bohr magneton. ${ }^{13}$ Maghemite $\left(\gamma-\mathrm{Fe}_{2} \mathrm{O}_{3}\right)$ is a kind of defect magnetite with only $\mathrm{Fe}(\mathrm{III})$ ions and vacancies in the spinal structure, whereas these vacancies are randomly distributed at the tetrahedral and octahedral sites.

It is obvious that within the structure, a higher magnetisation can be achieved if the $\mathrm{Fe}(\mathrm{III})$ in the tetrahedral sites is replaced by a non-magnetic element to basically "rule out the antagonist". However, there is no direct access to this sub-nano structure control, i.e., engineering at the atomic level can only be indirectly done by setting the right chemical conditions during the synthesis to achieve the desired result.

In fact, replacement of tetrahedral sites by several metal cations (that do not possess a magnetic moment) has been reported when these were present during nanoparticle synthesis. ${ }^{14-18}$ The most prominent candidate turned out to be zinc, which preferentially occupies the tetrahedral sites during wet-chemical bottom-up nanoparticle formation, and thus replaces Fe(III) and ultimately yields an overall increased magnetisation in magnetite nanoparticles. ${ }^{14,15,17}$

As stated, as there is no direct control on the atomic arrangement in the nanoparticles, this is rather a result of the chemical synthesis conditions, we herein investigated the sensitivity of the outcome with respect to the synthesis method. We studied the sub-nano structure of iron oxide nanoparticles undergoing $\mathrm{Zn}$ doping and found that the sub-nano structure can be very complex and differ in detail for different synthesis routes, although, superficially considered, the same well-known trend of increasing magnetisation with increasing $\mathrm{Zn}$ doping level was observed.

We compared the two most often reported methods to synthesise Zn doped magnetic iron oxide nanoparticles - the precursor co-precipitation and the thermal precursor decomposition route. The co-precipitation approach was done with two different bases, namely $\mathrm{NaOH}$ and $\mathrm{NH}_{3}$. These two bases are often used, however, to the best of our knowledge, they have not been studied with respect to their influence on the sub-nano structure upon formation of $\mathrm{Zn}$ doped magnetic iron oxide nanoparticles.

\section{Experimental}

\section{Materials}

Iron(III) chloride hexahydrate $\left(\mathrm{FeCl}_{3} \cdot 6 \mathrm{H}_{2} \mathrm{O}, 99 \%+\right)$, iron(II) chloride tetrahydrate $\left(\mathrm{FeCl}_{2} \cdot 4 \mathrm{H}_{2} \mathrm{O}, 99 \%+\right)$, iron(III) acetylacetonate $\left(\mathrm{Fe}(\mathrm{acac})_{3}\right.$, $97 \%+)$ and oleylamine $(70 \%+)$ were purchased from Sigma-Aldrich. Zinc chloride $\left(\mathrm{ZnCl}_{2}, 97 \%+\right)$, aqueous ammonia solution $\left(\mathrm{NH}_{3}\right.$ (aq.), $28-30 \mathrm{wt} \%)$ in water and sodium hydroxide $(\mathrm{NaOH}, 3 \mathrm{M})$ in water were purchased from Carl Roth. All chemicals were used without further purification.

\section{Synthesis of Zn doped iron oxide nanoparticles via co-precipitation}

The precipitation of zinc doped iron oxide nanoparticles was conducted using two different bases, namely sodium hydroxide 
$(\mathrm{NaOH})$ and aqueous ammonia $\left(\mathrm{NH}_{3}\right.$ (aq.)). Adequate amounts of $\mathrm{FeCl}_{3} \cdot 6 \mathrm{H}_{2} \mathrm{O}, \mathrm{FeCl}_{2} \cdot 4 \mathrm{H}_{2} \mathrm{O}$ and $\mathrm{ZnCl}_{2}$ were dissolved in deionised water in air at $20{ }^{\circ} \mathrm{C}$. Sodium hydroxide solution and aqueous ammonia solution, respectively, were added quickly under vigorous stirring. The black precipitate that formed was separated with a permanent handheld magnet after 1 min and washed three times with deionised water.

Samples synthesised with $\mathrm{NaOH}$ will be denoted as " $\mathrm{NaOH}$ ", samples synthesised with $\mathrm{NH}_{3}$ (aq.) will be denoted as " $\mathrm{NH}_{3}$ ", from now on.

\section{Synthesis of Zn doped iron oxide nanoparticles via thermal decomposition}

Following Mandel et al. ${ }^{19} 20 \mathrm{ml}$ of oleylamine was placed into a three neck flask. The flask was equipped with a reflux cooler, a magnetic stirrer, a heating mantle and a thermometer which measured the temperature of the liquid directly. After adding $3-x \mathrm{mmol}$ of $\mathrm{Fe}(\mathrm{acac})_{3}$ and $x \mathrm{mmol}$ of $\mathrm{ZnCl}_{2}$ (based on the formula $\mathrm{Zn}_{x} \mathrm{Fe}_{3-x} \mathrm{O}_{4}$ ) the temperature was raised to $350{ }^{\circ} \mathrm{C}$ whilst stirring. At $250{ }^{\circ} \mathrm{C}$ and $340{ }^{\circ} \mathrm{C}$ vigorous reactions were observed and the solution turned black, indicating the formation of nanoparticles. After $5 \mathrm{~min}$ of additional heating, the heating mantle was removed and the solution was allowed to cool down to room temperature. The nanoparticles were collected by adding an excess of ethanol which temporarily agglomerated the nanoparticles. Subsequently, the nanoparticles were washed with ethanol, acetone and cyclohexane using a handheld magnet and finally redispersed in cyclohexane. For co-precipitation, the base is the reactant that transforms the precursors to the final product state. For thermal decomposition, this is oleylamine (OA). Therefore, in the same manner as for the co-precipitation experiments, from now on the samples will be named after this ingredient, i.e., the products from thermal decomposition with different amounts of $\mathrm{Zn}$ are named "OA".

\section{Analyses methods}

VSM. Magnetic properties of the particles were recorded with a vibrating sample magnetometer (VSM, VersaLabTM 3T, Cryogen-free Vibrating Sample Magnetometer), cycling the applied field from -30 to +30 kOe two times with a step rate of $100 \mathrm{Oe} \mathrm{s}^{-1}$. Detailed analyses were carried out by cycling the applied field from -5 to $+5 \mathrm{kOe}$ at $5 \mathrm{Oe} \mathrm{s}^{-1}$. The temperature was set to $293 \mathrm{~K}\left(20^{\circ} \mathrm{C}\right)$ to study the behaviour of the particles at room temperature.

ICP-OES. The chemical composition of the precipitated materials was analysed with inductively coupled plasma optical emission spectroscopy (ICP-OES) using a Varian Vista-Pro CCD simultaneous ICP-OES. The samples synthesised by precipitation were digested in hydrochloric acid. The samples synthesised by thermal decomposition were digested in a mixture of hydrochloric acid and nitric acid.

Mössbauer. The ${ }^{57} \mathrm{Fe}$ Mössbauer absorption spectra have been measured at room temperature utilising ${ }^{57}$ Co source in $\mathrm{Rh}$ matrix. A Mössbauer spectrometer of an electromechanical type was used in the constant-acceleration mode. The $14.4 \mathrm{keV}$ $\gamma$-rays were detected with a proportional counter. The velocity scale was calibrated at room temperature with a metallic iron foil.
The low temperature spectra were analysed by means of leastsquares fitting procedure with a number of magnetically-split spectrum components corresponding to different iron positions.

XANES. X-ray absorption near edge spectroscopy (XANES) measurements were performed on $\mathrm{Zn}$ and Fe K-edges at SuperXAS beamline at the Swiss Light Source (SLS) synchrotron laboratory in Villigen. Spectra were recorded at ambient conditions using $\mathrm{K} \alpha$ partial fluorescence yield detection scheme. A fourelement SDD chip (made by Ketek) was placed in 45/90 degree (sample/detector) geometry with respect to the incoming X-ray beam monochromatised by a pair of flat $\mathrm{Si}(111)$ crystals. Measurements were performed on the composite of nanoparticles diluted in boron nitride powder pressed in the form of $\sim 1 \mathrm{~mm}$ thick pellets. The samples were prepared for optimum detection of the Zn dopants' spectra, while the Fe K-edge XANES spectra suffer from self-absorption and thus were corrected for.

TEM. Nanoparticles were deposited onto ultrathin carbon film on holey carbon. The structure, the shape and the size of the particles were studied using a transmission electron microscope (TEM) FEI Titan operating at $300 \mathrm{keV}$. Quantitative analysis of the TEM images was used to obtain the mean particle size and the size distribution for each series of the synthesised nanoparticles. This was done by fitting round circles around the lattice fringes of the nanoparticles and measuring their diameter. The sample size for each distribution was 60 nanoparticles.

\section{Results and discussion}

As described in the Experimental section, the precipitation of iron(II) together with iron(III) was done in the presence of 0-0.4 formula units of $\mathrm{Zn}$ in the formula $\mathrm{Zn}_{x} \mathrm{Fe}_{3-x} \mathrm{O}_{4}$, as formation of magnetite $\left(\mathrm{Fe}_{3} \mathrm{O}_{4}\right)$ from the syntheses was initially expected, following the assumptions of existing literature on doping iron oxide nanoparticles. The ratio of the metal ions was $\mathrm{Fe}(\mathrm{II}): \mathrm{Fe}(\mathrm{III}): \mathrm{Zn}(\mathrm{II})=1: 2-x: x$. All precipitation reactions were carried out either with $\mathrm{NaOH}$ or $\mathrm{NH}_{3}$ as the precipitant base. In the thermal decomposition method, iron(III) acetylacetonate was used without any other iron(II) source and $\mathrm{Zn}$ was offered in the same ratios.

Table 1 shows the theoretical formulae for each $\mathrm{Zn}$ doping level next to the formulae that were determined from ICP-OES (see Experimental section for details on the sample preparation that ensured that only the composition of the nanoparticles alone was measured).

It can be clearly seen that the actual $\mathrm{Zn}$ content only fits (with slight excess of $\mathrm{Zn}$ ) the set precursor ratios for the $\mathrm{NaOH}$ precipitation route ( $\mathrm{NaOH}$ samples). For the thermal decomposition route (OA samples), it can be seen that about $30-50 \%$ too little $\mathrm{Zn}$ is incorporated in the iron oxide structure. In which case, a less efficient $\mathrm{Zn}$ incorporation can be justified with very different reaction mechanisms probably occurring during nanoparticle formation. For instance, for this method a reduction of $\mathrm{Fe}(\mathrm{III})$ to $\mathrm{Fe}(\mathrm{II})$ occurs, which might disturb the $\mathrm{Zn}$ incorporation. However, what is remarkable is the different result for the precipitation route conducted with $\mathrm{NH}_{3}\left(\mathrm{NH}_{3}\right.$ samples). Although the 
Table 1 Theoretical amounts of zinc and theoretical formulae compared with the actual amounts of zinc determined via ICP-OES measurements with the respective determined formulae

\begin{tabular}{lllll}
\hline Samples & $\begin{array}{l}\text { Theoretical } \\
\text { amount of } \\
\text { zinc } x\end{array}$ & $\begin{array}{l}\text { Theoretical } \\
\text { formula }\end{array}$ & $\begin{array}{l}\text { Determined } \\
\text { amount of } \\
\text { zinc } x\end{array}$ & $\begin{array}{l}\text { Determined } \\
\text { formula }\end{array}$ \\
\hline NaOH & 0 & $\mathrm{Fe}_{3} \mathrm{O}_{4}$ & 0 & $\mathrm{Fe}_{3} \mathrm{O}_{4}$ \\
& 0.1 & $\mathrm{Zn}_{0.1} \mathrm{Fe}_{2.9} \mathrm{O}_{4}$ & 0.12 & $\mathrm{Zn}_{0.12} \mathrm{Fe}_{2.88} \mathrm{O}_{4}$ \\
& 0.2 & $\mathrm{Zn}_{0.2} \mathrm{Fe}_{2.8} \mathrm{O}_{4}$ & 0.23 & $\mathrm{Zn}_{0.23} \mathrm{Fe}_{2.77} \mathrm{O}_{4}$ \\
& 0.3 & $\mathrm{Zn}_{0.3} \mathrm{Fe}_{2.7} \mathrm{O}_{4}$ & 0.34 & $\mathrm{Zn}_{0.34} \mathrm{Fe}_{2.66} \mathrm{O}_{4}$ \\
& 0.4 & $\mathrm{Zn}_{0.4} \mathrm{Fe}_{2.6} \mathrm{O}_{4}$ & 0.44 & $\mathrm{Zn}_{0.44} \mathrm{Fe}_{2.56} \mathrm{O}_{4}$ \\
$\mathrm{NH}_{3}$ & 0 & & & \\
& 0.1 & $\mathrm{Fe}_{3} \mathrm{O}_{4}$ & 0 & $\mathrm{Fe}_{3} \mathrm{O}_{4}$ \\
& 0.2 & $\mathrm{Zn}_{0.1} \mathrm{Fe}_{2.9} \mathrm{O}_{4}$ & 0.07 & $\mathrm{Zn}_{0.07} \mathrm{Fe}_{2.93} \mathrm{O}_{4}$ \\
& 0.3 & $\mathrm{Zn}_{0.2} \mathrm{Fe}_{2.8} \mathrm{O}_{4}$ & 0.13 & $\mathrm{Zn}_{0.13} \mathrm{Fe}_{2.87} \mathrm{O}_{4}$ \\
& 0.4 & $\mathrm{Zn}_{0.3} \mathrm{Fe}_{2.7} \mathrm{O}_{4}$ & 0.19 & $\mathrm{Zn}_{0.19} \mathrm{Fe}_{2.81} \mathrm{O}_{4}$ \\
$\mathrm{Zn}_{0.4} \mathrm{Fe}_{2.6} \mathrm{O}_{4}$ & 0.22 & $\mathrm{Zn}_{0.22} \mathrm{Fe}_{2.78} \mathrm{O}_{4}$ \\
& & & & \\
& 0 & $\mathrm{Fe}_{3} \mathrm{O}_{4}$ & 0 & $\mathrm{Fe}_{3} \mathrm{O}_{4}$ \\
& 0.1 & $\mathrm{Zn}_{0.1} \mathrm{Fe}_{2.9} \mathrm{O}_{4}$ & 0.05 & $\mathrm{Zn}_{0.05} \mathrm{Fe}_{2.95} \mathrm{O}_{4}$ \\
& 0.19 & $\mathrm{Zn}_{0.19} \mathrm{Fe}_{2.81} \mathrm{O}_{4}$ & 0.09 & $\mathrm{Zn}_{0.09} \mathrm{Fe}_{2.91} \mathrm{O}_{4}$ \\
& 0.28 & $\mathrm{Zn}_{0.28} \mathrm{Fe}_{2.72} \mathrm{O}_{4}$ & 0.15 & $\mathrm{Zn}_{0.15} \mathrm{Fe}_{2.85} \mathrm{O}_{4}$ \\
& 0.37 & $\mathrm{Zn}_{0.37} \mathrm{Fe}_{2.63} \mathrm{O}_{4}$ & 0.15 & $\mathrm{Zn}_{0.15} \mathrm{Fe}_{2.85} \mathrm{O}_{4}$ \\
& 0.45 & $\mathrm{Zn}_{0.45} \mathrm{Fe}_{2.55} \mathrm{O}_{4}$ & 0.31 & $\mathrm{Zn}_{0.31} \mathrm{Fe}_{2.69} \mathrm{O}_{4}$ \\
& & &
\end{tabular}

precipitation with $\mathrm{NH}_{3}$ is conducted exactly in the same manner as with $\mathrm{NaOH}$, the $\mathrm{Zn}$ incorporation is about $30-45 \%$ below the envisaged amount and apparently cannot exceed a content $x$ of about 0.22 . This is a first indication that the structures might be quite distinct because of only slightly different synthesis conditions.

Fig. 2 shows the saturation magnetisations of the particles at 30000 Oe as a function of the actual $\mathrm{Zn}$ doping for the three synthesis cases (all magnetisation curves can be found in the ESI $\dagger$ ). It can be seen, that the magnetisation increases with increasing $\mathrm{Zn}$ content in the same manner for the three series. (It is also observed that for the "OA" series, the jump in saturation magnetisation upon $\mathrm{Zn}$ doping is quite remarkable. However, for this particular observation, the authors to date have not found any explanation.)

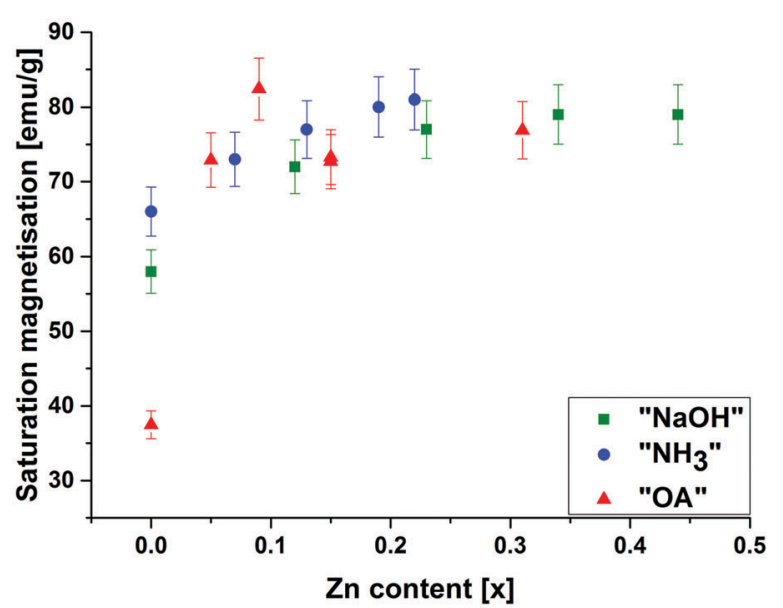

Fig. 2 Saturation magnetisation (measured at $30000 \mathrm{Oe}$ ) as a function of the actual $\mathrm{Zn}$ content $x$ in the structure $\mathrm{Zn}_{x} \mathrm{Fe}_{3-x} \mathrm{O}_{4}$ for the three different sample types "NaOH", "NH$H_{3}$ " and "OA".
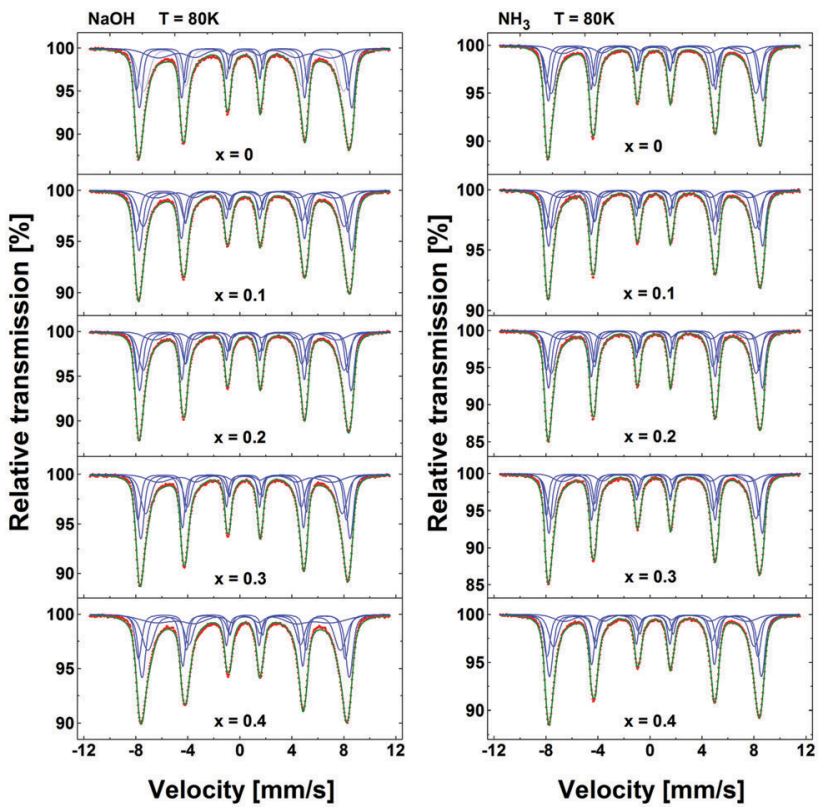

Fig. $3{ }^{57} \mathrm{Fe}$ Mössbauer spectra of " $\mathrm{NH}_{3}$ " and "NaOH" series of nanoparticles collected at $T=80$ K. N.B. $x$ denotes the sample with the designated $\mathrm{Zn}$ content here. The actual content, as listed in Table 1, was found to differ with respect to the synthesis method. The red dots represent experimental spectrum, while the green solid line is a result of the numerical fit using three or four components (blue lines) corresponding to different iron sites of the spinel and surface iron ions.

To find out more about the sub-nano structure of the particles, the three systems were at first examined with Mössbauer spectroscopy (MS).

The results of MS measurements performed at $T=80 \mathrm{~K}$ on all the samples of $\mathrm{NaOH}$ and $\mathrm{NH}_{3}$ series are shown in Fig. 3. The spectra of undoped samples $(x=0)$ reveal a characteristic shape of multisite iron oxide - broadened sextet. No significant evolution of the spectral shape was observed for $\mathrm{NaOH}$ and $\mathrm{NH}_{3}$ series upon $\mathrm{Zn}$ doping, except for a gradual increase of mean isomer shift, $\langle\mathrm{IS}\rangle$, and a small variation of the mean hyperfine field, $\langle H\rangle$.

MS spectra of the OA series (Fig. 4) show a wide, broadened sextet, similar to the other series. However, they reveal additional narrow features characterised by weaker hyperfine fields and distinct isomer shift. The latter is attributed to significant amounts of spurious phases, namely cementite $\left(\mathrm{Fe}_{3} \mathrm{C}\right)$ and iron $(\alpha-\mathrm{Fe})$ that are present in various amounts in all the samples of the OA series.

Mössbauer spectra were also collected at $T=300 \mathrm{~K}$. Contrary to low temperature spectra, they show a distinct shape for each series of NPs (Fig. 5). All compounds containing unpaired valence or conduction electrons, should show a magnetic hyperfine field, $B_{\mathrm{hf}}$. However, the electronic spins which generate $B_{\mathrm{hf}}$ are subject to changes of direction due to the electronic spin relaxation persisting within the observation time scale, which is in Mössbauer spectroscopy of order of $10^{-8} \mathrm{~s}$. The electronic spins which generate $B_{\mathrm{hf}}$ are subject to changes of direction due to the electronic spin relaxation. This can be due to a competition between energies of magnetic anisotropy and thermal fluctuations. 

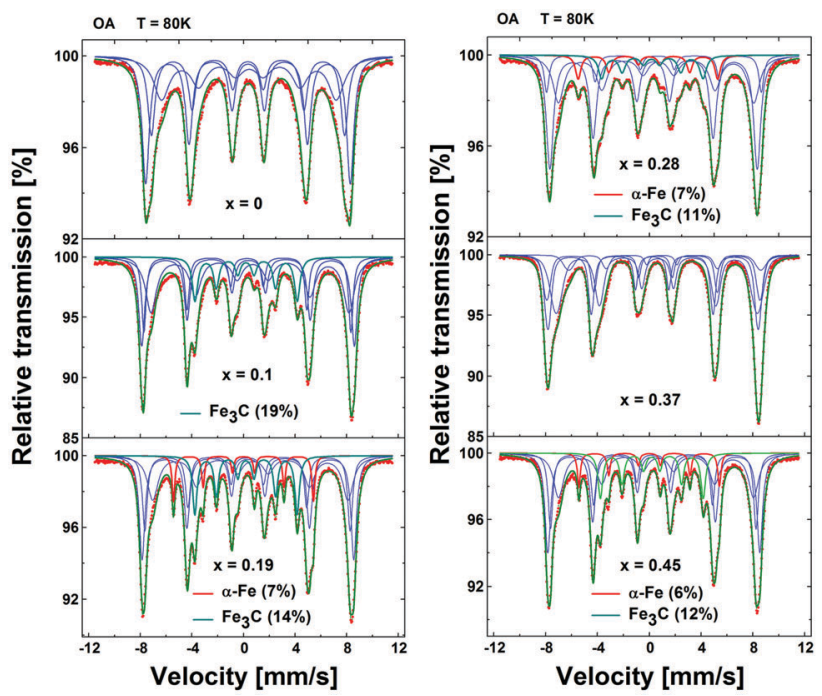

Fig. $4{ }^{57} \mathrm{Fe}$ Mössbauer spectra of "OA" series of nanoparticles collected at $T=80 \mathrm{~K}$. The relative area of $\mathrm{Fe}_{3} \mathrm{C}$ and $\alpha$-Fe features is listed within the figure. N.B. $x$ denotes the sample with the designated $\mathrm{Zn}$ content here. The actual content, as listed in Table 1, was found to differ with respect to the synthesis method.

In paramagnetic compounds, the spin relaxation is usually rapid and results in $B_{\mathrm{hf}}$ being time averaged to zero so that no magnetic splitting and only a single line (or doublet) is seen. There are, however, intermediate possibilities where the electronic spins relax on a time scale comparable with that of the nuclear transition, and these result in more complicated relaxation spectra. This effect is well seen in the spectra of our nanoparticles also collected at $T=300 \mathrm{~K}$. Contrary to low temperature spectra (with clearly visible magnetic splitting and well defined $B_{\mathrm{hf}}$ ), they show a distinct shape for each series of NPs (Fig. 5). Since the anisotropy energy depends on the anisotropy constant, $K$, and nanoparticle's volume, this can either be explained from a different average size for each of the nanoparticle series or by a different $K$ as a result of an increasing structural disorder. A qualitative comparison of the Mössbauer spectra to that reported for $\mathrm{ZnFe}_{2} \mathrm{O}_{4}$ nanoparticles ${ }^{20}$ suggests that the average diameter of $\mathrm{NaOH}$ series is of the order of $10 \mathrm{~nm}$. Following this interpretation, a deviating spectrum, as observed for $\mathrm{NH}_{3}$ and $\mathrm{OA}$, could be assigned simply to a different diameter of the particles of the other series. However, TEM images (Fig. 6) reveal that the precipitated particles $\left(\mathrm{NaOH}\right.$ and $\left.\mathrm{NH}_{3}\right)$ are about $8-10 \mathrm{~nm}$ in diameter. The OA-samples show a larger size of up to $15 \mathrm{~nm}$ in diameter (for detailed information on the size distribution of the samples see the ESI $\dagger$ ). Therefore, at least for the $\mathrm{NaOH}$ and the $\mathrm{NH}_{3}$ series, the explanation for the deviation in the Mössbauer spectra has to be related to differences in magnetic anisotropy most likely resulting from the structural order within the nanoparticles and not to differences in size (see below). The $80 \mathrm{~K}$ and $300 \mathrm{~K}$ spectra for the samples doped with $\mathrm{Zn}$ are very similar to the spectra of the undoped samples, except for the samples produced by OA. The thermal decomposition seems to deviate, resulting in the formation of not only magnetite but also of different Fe phases.

The mean isomer shift $\langle$ IS $\rangle$ in the Mössbauer spectra indicates that all of the iron ions have a formal valence of $3+$ (Fig. 7). There is a constant increase of $\langle$ IS $\rangle$ observable, however, the values reached are still far below the $\langle$ IS $\rangle$ value 0.523 reported for magnetite. ${ }^{21,22}$ The values observed for the $\mathrm{NH}_{3}$ and $\mathrm{NaOH}$ series are confined between 0.33 and 0.35 . The observed increase of $\langle$ IS $\rangle$ with increasing $\mathrm{Zn}$ doping is most probably due to a change of the lattice parameter.

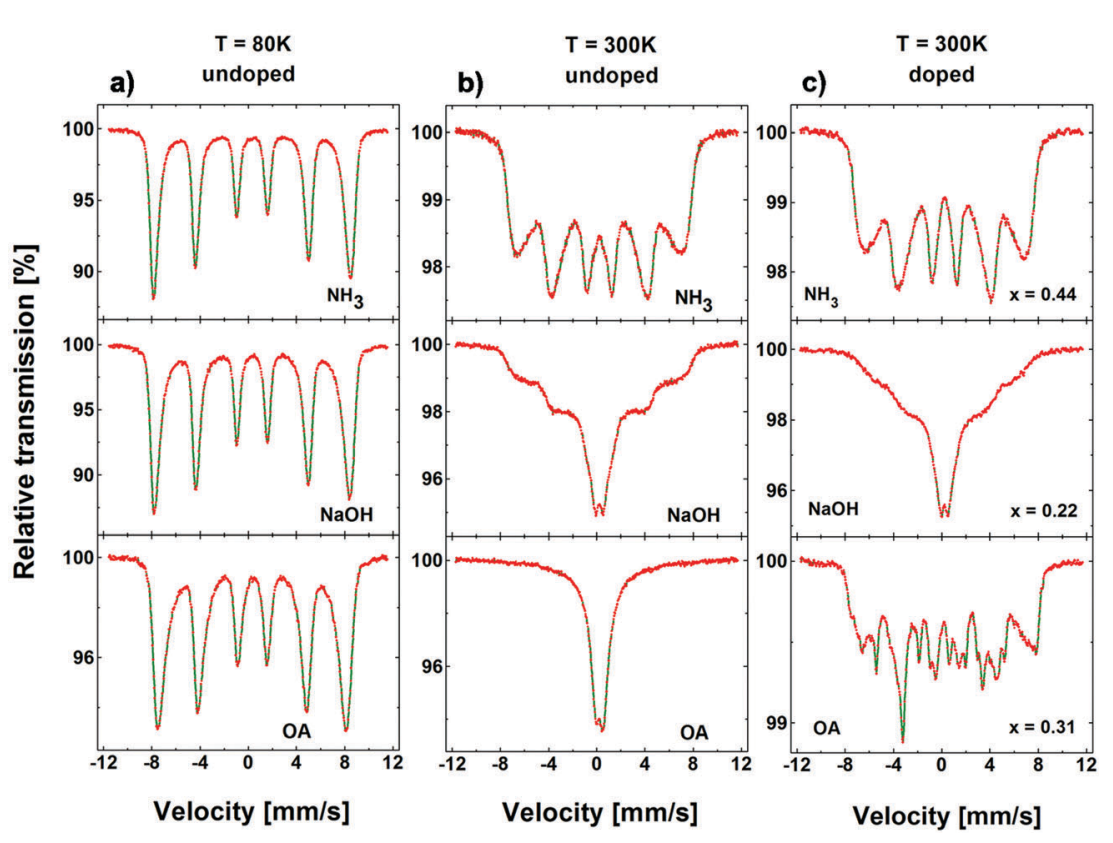

Fig. 5 Comparison of the ${ }^{57} \mathrm{Fe}$ Mössbauer spectra collected at $T=80 \mathrm{~K}(\mathrm{a})$, and $300 \mathrm{~K}$ (b), from undoped samples of each series. Comparison of the ${ }^{57} \mathrm{Fe}$ Mössbauer spectra collected at $T=300 \mathrm{~K}$ of the undoped (b), with the most doped (c), samples of each series. 


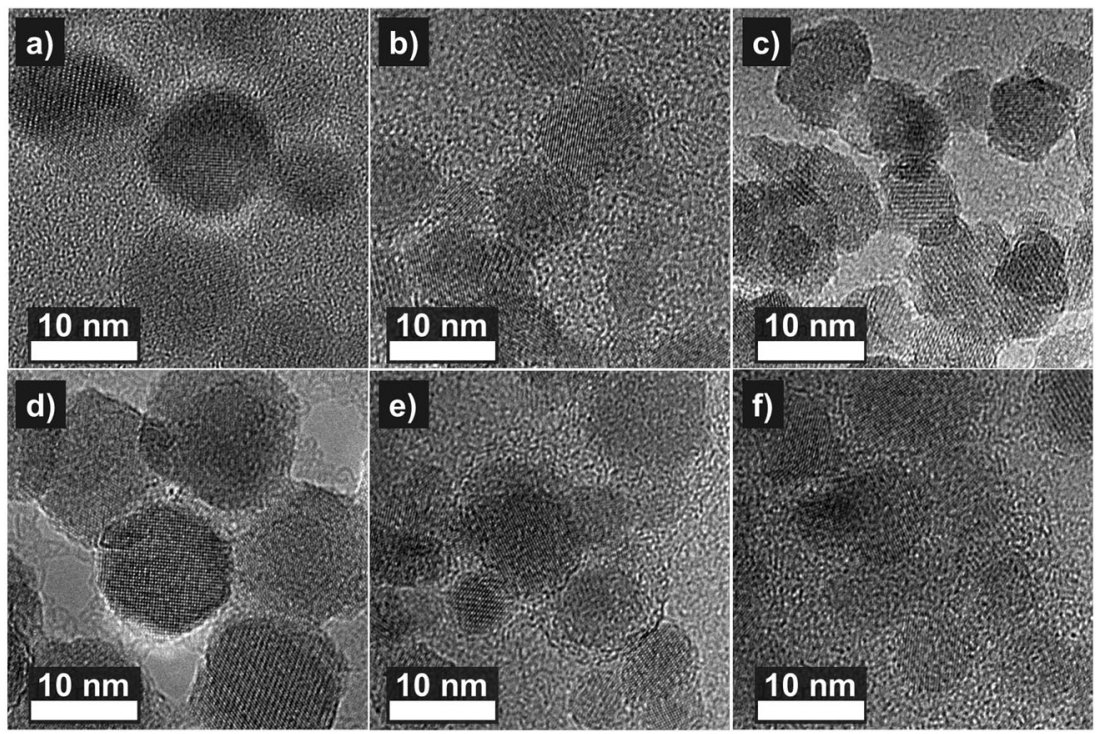

Fig. 6 HRTEM images of $\mathrm{Zn}$ doped (a) $\mathrm{OA}$, (b) $\mathrm{NaOH}$, and (c) $\mathrm{NH}_{3}$ series with the respective highest amount of $\mathrm{Zn}$ and undoped (d) $\mathrm{OA}$, (e) $\mathrm{NaOH}$, (f) $\mathrm{NH}$ series nanoparticles.
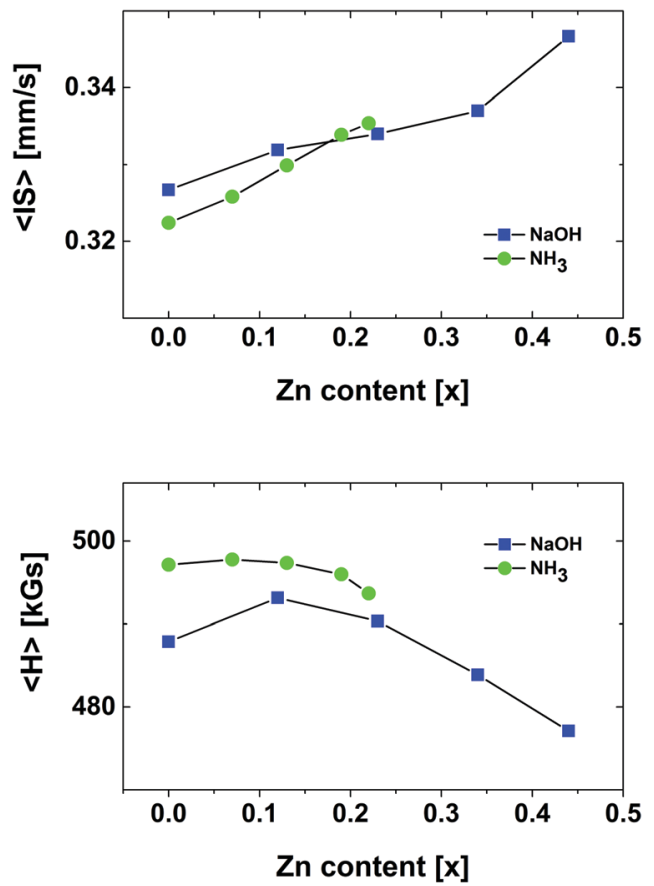

Fig. 7 Mean isomer shift $\langle\mathrm{IS}\rangle$ and mean hyperfine field $\langle H\rangle$ from ${ }^{57} \mathrm{Fe}$ Mössbauer $T=80 \mathrm{~K}$, for the $\mathrm{NH}_{3}$ and $\mathrm{NaOH}$ series as a function of the actual $\mathrm{Zn}$ doping $(x)$. The OA series did not show any systematic dependency of these parameters on $x$ and is therefore not shown.

The mean hyperfine field $\langle H\rangle$ (Fig. 7) is close to the value of $\mathrm{Fe}_{3} \mathrm{O}_{4} \cdot{ }^{20}$ Hence, it is a spinel structured $\mathrm{Fe}(\mathrm{III})$ oxide. Upon $\mathrm{Zn}$ doping the $\langle H\rangle$ value increases, which is caused by an increased occupancy of the cationic sublattice up to approx. $x=0.2$, for both $\mathrm{NaOH}$ and $\mathrm{NH}_{3}$ series. The particles of the $\mathrm{NaOH}$ series are capable of receiving more $\mathrm{Zn}$. However, for $x>0.2$ a decrease of $\langle H\rangle$ is observable. The $O_{\mathrm{h}}$ sublattice of iron is disturbed by $\mathrm{Zn}$ ions entering the $O_{\mathrm{h}}$ sublattice.
The nanoparticles of the $\mathrm{NH}_{3}$ series are magnetically well ordered, whereas the $\mathrm{NaOH}$ series exhibits a larger degree of magnetic disorder. This is evident from the relaxation MS spectra at RT (Fig. 5) and the saturation magnetisation values (Fig. 2).

The OA series shows the presence of significant amounts of other phases in the MS spectra, namely metallic iron and cementite. The relaxation MS spectrum at RT of the undoped sample indicates a highly disordered structure. This correlates well with the low saturation magnetisation of this sample. The mean $\langle$ IS $\rangle$ and $\langle H\rangle$ values for the OA series are provided in Table 2. Since the samples of OA series consist of many phases of unlike magnetic and electronic properties the quantitative values of mean hyperfine parameters are meaningless. As there is no clear dependence on the $\mathrm{Zn}$ content, the values are not plotted.

To delve further into the sub-nano/atomic structure of the particles, XANES was performed at the Fe, as well as at the $\mathrm{Zn}$ K-edge. Iron K-edge X-ray absorption spectra were collected from two end member samples of each series, namely undoped and the most doped ones (Fig. 8).

The findings from the Mössbauer spectroscopy correlate well with the XANES spectra recorded for the undoped samples and maximally doped samples.

Table 2 Mean $\langle\mathrm{IS}\rangle$ and $\langle H\rangle$ values for the OA series recorded at $80 \mathrm{~K}$ as function of the $\mathrm{Zn}$ content

\begin{tabular}{|c|c|c|c|c|c|c|}
\hline \multirow[b]{2}{*}{ Sample } & \multicolumn{2}{|c|}{ Zinc amount $x$} & \multicolumn{2}{|c|}{$\langle\mathrm{IS}\rangle\left[\mathrm{mm} \mathrm{s}^{-1}\right]$} & \multicolumn{2}{|c|}{$\langle H\rangle[\mathrm{kG}$ s] } \\
\hline & Theoret. & $\begin{array}{l}\text { As } \\
\text { determined }\end{array}$ & $\begin{array}{l}\text { Ferrite } \\
\text { phase }\end{array}$ & $\begin{array}{l}\text { All } \\
\text { phases }\end{array}$ & $\begin{array}{l}\text { Ferrite } \\
\text { phase }\end{array}$ & $\begin{array}{l}\text { All } \\
\text { phases }\end{array}$ \\
\hline \multirow[t]{6}{*}{$\mathrm{OA}$} & 0 & 0 & 0.48 & 0.48 & 463 & 463 \\
\hline & 0.1 & 0.05 & 0.56 & 0.52 & 493 & 459 \\
\hline & 0.19 & 0.09 & 0.54 & 0.47 & 492 & 445 \\
\hline & 0.28 & 0.15 & 0.55 & 0.51 & 488 & 456 \\
\hline & 0.37 & 0.15 & 0.61 & 0.61 & 491 & 491 \\
\hline & 0.45 & 0.31 & 0.53 & 0.48 & 490 & 451 \\
\hline
\end{tabular}



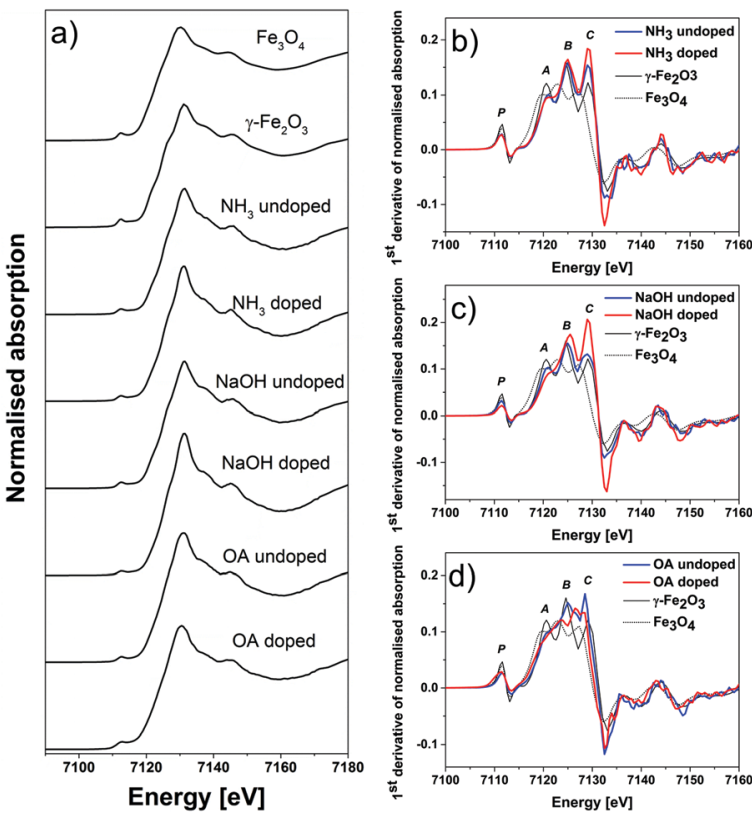

Fig. 8 Fluorescence detected Fe K-edge XANES spectra (left) and their first derivative (right panels, b: $\mathrm{NH}_{3}, \mathrm{c}: \mathrm{NaOH}, \mathrm{d}$ : $\mathrm{OA}$ ) collected from reference oxides and the representative samples of each series, namely the undoped ones and those of highest $\mathrm{Zn}$ content.

The spectra of the $\mathrm{NH}_{3}$ series do not show much evolution from the undoped to the doped state, as is the case for MS. The spectra show high similarity with the XANES spectrum of $\gamma-\mathrm{Fe}_{2} \mathrm{O}_{3}$. This is especially good to see when analysing the 1st derivative of normalised spectra (Fig. 8b). The positions of the distinctive peaks of the main maximum, A, B and C, match exactly those of $\gamma-\mathrm{Fe}_{2} \mathrm{O}_{3}$ reference spectra, as does the position of the slopes of the main maximum. These positions do not change upon doping. However, C increases significantly. From simulations it is known that features $\mathrm{P}$ and A are primarily sensitive to changes in the occupation of the tetrahedral sites, whereas features $\mathrm{B}$ and $\mathrm{C}$ are sensitive to octahedral sites. ${ }^{23}$ Thus, one can see that for the iron ions the (relative) occupancy at the octahedral sites increases upon doping, whereas the tetrahedral sites remain unaffected.

The spectra of the reference oxides were recorded on bulk samples in transmission mode and are self-absorption free. Therefore, the intensities of the features are expected to be different, but the positions are the same. Thus, one can only judge on the relative changes in the occupancies between doped and undoped NPs of the same series.

In the case of the $\mathrm{NaOH}$ series the spectral features of Fe K-edge XANES (Fig. 8c) have the positions of the $\gamma-\mathrm{Fe}_{2} \mathrm{O}_{3}$ reference, too. However, for this series a significant decrease in the occupation of Fe ions at the tetrahedral sites is observed upon $\mathrm{Zn}$ doping features $\mathrm{P}$ and A. Additionally, a strong increase of the Fe occupation at octahedral sites is evident - features B and C.

The XANES spectra of the OA support the findings from the Mössbauer spectroscopy. The undoped sample is Fe(III) oxide, with Fe both in octahedral and tetrahedral sites. However, it is strongly disordered. Zn doping distorts the structure even more. The pre-peak $\mathrm{P}$ shows a shoulder at lower energies. This is an

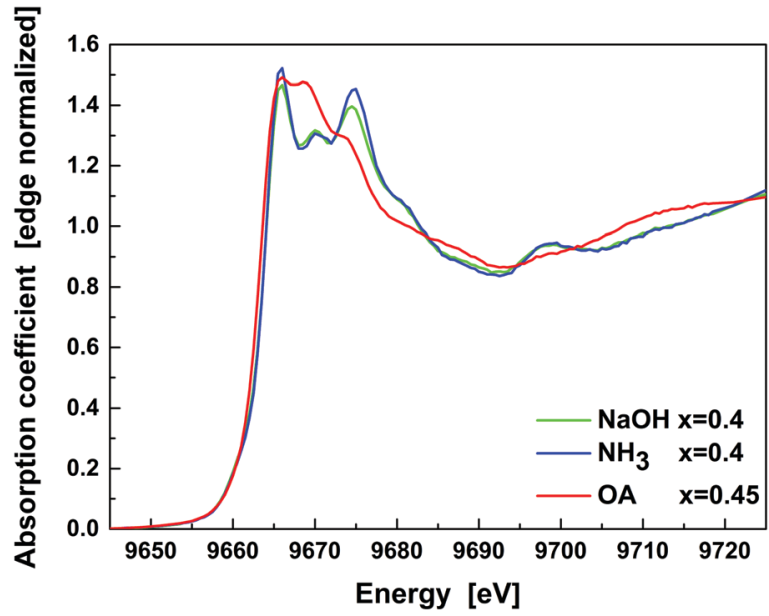

Fig. 9 Fluorescence detected Zn K-edge XANES spectra of NP samples with the highest $Z n$ content. N.B. $x$ denotes the sample with the designated $Z n$ content here. The actual content, as listed in Table 1, was found to differ with respect to the synthesis method.

indication of the presence of metallic-like phases. ${ }^{24}$ The main maximum is shifted to lower energies, thus the mean formal valence of the doped material is lower than $\mathrm{Fe}^{3+} \cdot{ }^{25}$

The doped NP samples (of highest $\mathrm{Zn}$ content) of all three series studied were also probed at the $\mathrm{Zn}$ K-edge (Fig. 9). The $\mathrm{NH}_{3}$ and $\mathrm{NaOH}$ sample spectra show a characteristic shape of $\mathrm{Zn}$-ferrites that consist of three peaks between $9665 \mathrm{eV}$ and $9675 \mathrm{eV}^{26}$ Their relative intensity is typically considered as a fingerprint of the spinel inversion, namely the amount of $\mathrm{Zn}$ in octahedral sites. Most experimental and theoretical work reports that the relative intensity of the middle peak rises with inversion, ${ }^{27}$ while the first and third peaks are usually identical in intensity. In our case, the $\mathrm{NPs}$ of $\mathrm{NH}_{3}$ and $\mathrm{NaOH}$ series show a predominantly normal spinel structure $\left(\mathrm{Zn}^{2+}\right.$ occupying tetrahedral sites). This is especially valid for the $\mathrm{NH}_{3}$ series, where $\mathrm{Zn}$ is found only at the $T_{\mathrm{d}}$ sites. However, in the case of the $\mathrm{NaOH}$ series some $\mathrm{Zn}$ is additionally found at $O_{\mathrm{h}}$ sites, owing to the twice as high $\mathrm{Zn}$ content of the maximally doped samples with respect to that of the $\mathrm{NH}_{3}$ series. The spectrum of the OA series sample shows the three maxima, with the strongest middle peak (Zn occupying octahedral sites). However, the overall shape of the absorption edge is strongly modified. It is ascribed to a significant admixture of a $\mathrm{ZnO}$ phase.

Taking together all of these findings, the following interpretations can be made.

\section{OA series}

The doping of the iron oxide nanoparticles with $\mathrm{Zn}$ causes decomposition into different phases. The main part is still the pristine iron oxide phase, most probably $\gamma-\mathrm{Fe}_{2} \mathrm{O}_{3}$. Additionally, the spectroscopy techniques employed detected significant amounts of metallic $\alpha$-Fe, cementite $\left(\mathrm{Fe}_{3} \mathrm{C}\right)$, and zinc oxide, however, these phases only prevail as traces and are difficult to reveal.

\section{$\mathrm{NaOH}$ series}

The iron oxide nanoparticles have the structure of a simple spinel, the spectroscopy results suggest $\gamma-\mathrm{Fe}_{2} \mathrm{O}_{3}$. The overall structural 
order is not as good as for the $\mathrm{NH}_{3}$ series. Due to this lower order, it is easier for $\mathrm{Zn}$ to be incorporated. As found from ICP-OES, Zn can be incorporated to a much higher level compared to the $\mathrm{NH}_{3}$ series. From XANES it was found that this can be explained by $\mathrm{Zn}$ being able to enter both the tetrahedral as well as the octahedral positions at high doping levels. This is apparently only possible due to the low-ordered structure of the particles from the $\mathrm{NaOH}$ series.

\section{$\mathrm{NH}_{3}$ series}

The iron oxide nanoparticles have the structure of a simple spinel, the spectroscopy results suggest predominantly the structure of $\gamma-\mathrm{Fe}_{2} \mathrm{O}_{3}$. The particles of this series have the best (magnetically) ordered structure among all particle series, as Mössbauer spectroscopy and XANES suggest. Most probably, due to this well ordered structure, there is a limit for the maximum possible $\mathrm{Zn}$ incorporation (as it was found from ICP-OES). $\mathrm{Zn}$ only occupies the tetrahedral positions and only up to a maximum of $x=0.22$.

\section{General valid for $\mathrm{NaOH}$ and $\mathrm{NH}_{3}$ series}

It cannot be excluded that the particles that initially formed were rather magnetite like, i.e., contained $\mathrm{Fe}(\mathrm{II})$, and post synthesis oxidation during sampling handling caused a progressive oxidation to Fe(III) species. However, apparently the oxidation state of Fe prevailing as the stable form in the particles is Fe(III). Nevertheless, it should be noted that during precipitation syntheses, the presence of $\mathrm{Fe}(\mathrm{II})$ is crucial to form spinel oxides, and no oxyhydroxides would form if only $\mathrm{Fe}(\mathrm{III})$ was present.

With respect to $\mathrm{Zn}$ uptake, the question remains as to why the difference between $\mathrm{NH}_{3}$ and $\mathrm{NaOH}$ precipitation is so remarkable. At this stage, this difference has just been observed as a fact and the authors have no explanation yet for the difference. It can only be speculated that the precipitation kinetics is different for the two bases $\left(\mathrm{NaOH}\right.$ is a much stronger base than $\left.\mathrm{NH}_{3}\right)$. Potentially, also the evolution of $\mathrm{Zn}$ doped iron oxide nanocrystals via hydrolysis and condensation reactions upon $\mathrm{pH}$ increase take place in a very different manner just when the base (coming with all its specific properties) is changed. A detailed study on the reaction mechanism would go way beyond this work as, for instance, the oxyhydroxide formation from iron(III) alone is a remarkably complex field. ${ }^{28}$ Additionally, sodium might play a role in the structure differences, as other than $\mathrm{NH}_{3}$ the sodium ions are not volatile components.

\section{Conclusion}

From all the findings reported in this work, it can ultimately be concluded that as expected, $\mathrm{Zn}$ acts as a dopant to iron oxide nanoparticles resulting in increased magnetisation. This holds for different synthesis methods such as co-precipitation and thermal decomposition. However, the textbook reaction, namely that iron(III) is replaced by $\mathrm{Zn(II)}$ at the tetrahedral sites, whereas the rest of the nanocrystal structure stays unaffected, turned out to be not generalised. We also found that, when starting to look in very close detail into the structure of iron oxides with various spectroscopy techniques, new features can be unravelled. For instance, our own previous work also assumed a predominant magnetite character for the precipitated iron oxide nanoparticles in accordance with most of the existing literature. However, our latest findings show that there is more structural complexity even behind the simple and well established precipitation routes. Of course, this complexity drastically increases upon atomically changing the magnetic ordering within nanoparticles via doping. Thus, the report here shows that it is crucial to very precisely study the obtained structures when "playing" with the atomic order in iron oxide nanocrystals.

\section{Acknowledgements}

The Swiss Light Source/Paul Scherrer Institute, Switzerland, is acknowledged for granting beam time. Jan Żukrowski and Marcin Sikora acknowledge support from the National Science Centre, Poland (grant 2014/14/E/ST3/00026).

\section{References}

1 A. K. Gupta and M. Gupta, Biomaterials, 2005, 26, 3995-4021.

2 Z. Li, L. Wei, M. Y. Gao and H. Lei, Adv. Mater., 2005, 17, 1001-1005.

3 S. Mornet, S. Vasseur, F. Grasset, P. Veverka, G. Goglio, A. Demourgues, J. Portier, E. Pollert and E. Duguet, Prog. Solid State Chem., 2006, 34, 237-247.

4 A.-H. Lu, W. Schmidt, N. Matoussevitch, H. Bönnemann, B. Spliethoff, B. Tesche, E. Bill, W. Kiefer and F. Schüth, Angew. Chem., 2004, 116, 4403-4406.

5 S. C. Tsang, V. Caps, I. Paraskevas, D. Chadwick and D. Thompsett, Angew. Chem., 2004, 116, 5763-5767.

6 S. Chikazumi, S. Taketomi, M. Ukita, M. Mizukami, H. Miyajima, M. Setogawa and Y. Kurihara, J. Magn. Magn. Mater., 1987, 65, 245-251.

7 D. W. Elliott and W.-x. Zhang, Environ. Sci. Technol., 2001, 35, 4922-4926.

8 M. Takafuji, S. Ide, H. Ihara and Z. Xu, Chem. Mater., 2004, 16, 1977-1983.

9 T. Hyeon, Chem. Commun., 2003, 927-934.

10 R. M. Cornell and U. Schwertmann, The Iron Oxides: Structure, Properties, Reactions, Occurences and Uses, Wiley-VCH, Weinheim, 2nd edn, 2003.

11 Advances in Chemical Physics, ed. J. L. Dormann, D. Fiorani and E. Tronc, Wiley, Hoboken, 1997, vol. 98.

12 Magnetic Nanoparticles, ed. Y. A. Koksharov, Wiley-VCH, Weinheim, 2009.

13 J. M. D. Coey, Magnetism and Magnetic Materials, Cambridge University Press, New York, 2010.

14 J. Liu, Y. Bin and M. Matsuo, J. Phys. Chem. C, 2012, 116, 134-143.

15 S. S. Pati and J. Philip, J. Appl. Phys., 2013, 113, 44314.

16 J.-t. Jang, H. Nah, J.-H. Lee, S. H. Moon, M. G. Kim and J. Cheon, Angew. Chem., Int. Ed., 2009, 48, 1234-1238. 
17 Y. Yang, X. Liu, Y. Yang, W. Xiao, Z. Li, D. Xue, F. Li and J. Ding, J. Mater. Chem. C, 2013, 1, 2875.

18 S. Mohapatra, S. R. Rout and A. B. Panda, Colloids Surf., A, 2011, 384, 453-460.

19 K. Mandel, F. Dillon, A. A. Koos, Z. Aslam, F. Cullen, H. Bishop, A. Crossley and N. Grobert, RSC Adv., 2012, 2, 3748-3752.

20 L. Rebbouh, R. P. Hermann, F. Grandjean, T. Hyeon, K. An, A. Amato and G. J. Long, Phys. Rev. B: Condens. Matter Mater. Phys., 2007, 76, 174422.

21 G. M. da Costa, C. Blanco-Andujar, E. de Grave and Q. A. Pankhurst, J. Phys. Chem. B, 2014, 118, 11738-11746.

22 S. Braccini, O. Pellegrinelli and K. Krämer, World J. Nucl. Sci. Technol., 2013, 3, 91-95.
23 R. Sato Turtelli, M. Atif, N. Mehmood, F. Kubel, K. Biernacka, W. Linert, R. Grössinger, C. Kapusta and M. Sikora, Mater. Chem. Phys., 2012, 132, 832-838.

24 M. Wilke, F. Farges, P.-E. Petit, G. E. Brown and F. Martin, Am. Mineral., 2001, 86, 714-730.

25 T. E. Westre, P. Kennepohl, J. G. DeWitt, B. Hedman, K. O. Hodgson and E. I. Solomon, J. Am. Chem. Soc., 1997, 119, 6297-6314.

26 J. A. Gomes, G. M. Azevedo, J. Depeyrot, J. Mestnik-Filho, G. J. da Silva, F. A. Tourinho and R. Perzynski, J. Magn. Magn. Mater., 2011, 323, 1203-1206.

27 S. J. Stewart, S. J. A. Figueroa, J. M. Ramallo López, S. G. Marchetti, J. F. Bengoa, R. J. Prado and F. G. Requejo, Phys. Rev. B: Condens. Matter Mater. Phys., 2007, 75, 73408.

28 C. M. Flynn, Jr., Chem. Rev., 1984, 84, 31-41. 